\title{
RELATAR LA EXPERIENCIA DOCENTE. LA DOCUMENTACIÓN NARRATIVA DEL MUNDO ESCOLAR
}

Daniel H. Suárez ${ }^{(*)}$

\section{OTRAS HISTORIAS SOBRE EL MUNDO ESCOLAR}

La escuela siempre estuvo atravesada por expectativas sociales y proyectos políticos para la formación social, la socialización política y la preparación laboral de las nuevas generaciones. Tal vez por eso, y en un escenario de permanente disputa, la institución escolar siempre estuvo interpelada por discursos públicos y especializados acerca de su tarea, su organización y su disponibilidad: los discursos políticos, sociales y pedagógicos, hegemónicos y alternativos, pugnan por demarcar sus alcances, potencialidades y límites. Además, por su inclusión en un sistema complejo, de escala cuasi universal, que pretende actualizar esas expectativas y proyectos, siempre resultó imperioso generar cierta previsibilidad y proyección de las tareas y acciones escolares. Las necesidades de la administración y la gestión de los modernos y masivos sistemas educativos hacen que la actividad escolar requiera ser organizada, planificada y regulada de acuerdo a normas, criterios y procedimientos bien estipulados, objetivados, escritos y sancionados: leyes, resoluciones ministeriales, diseños curriculares, disposiciones y circulares administrativas, programas $\mathrm{y}$ planificaciones.

Pero más allá de este persistente esfuerzo por prever y controlar el acontecer en las escuelas, una parte significativa de las acciones humanas que se despliegan cotidianamente en ellas emergen y se improvisan en la cotidianeidad de la vida escolar. Aún en las ocasiones en que la actividad escolar pretenda ser prescripta y programada de manera minuciosa y obsesiva, el encuentro pedagógico entre docentes y alumnos siempre estará connotado por la polisemia y la incertidumbre que acompañan a todas las interacciones sociales. Los proyectos educativos, inclusive los científicamente validados y técnicamente calibrados, no tendrían ningún efecto sobre el mundo escolar, si los directivos y docentes no los hicieran propios, los adaptaran a sus propias imaginaciones, expectativas y proyectos, los ajustaran a sus propias percepciones de los problemas, los rediseñaran a la escala particular y singularidad de sus escuelas y aulas, los dijeran con sus propias voces y los escribieran con las mismas palabras que usan para darle sentido y construir

${ }^{(*)}$ Facultad de Filosofía y Letras / Universidad de Buenos Aires E-mail: danielhugosuarez@gmail.com. 
significado en torno de lo que hacen, experimentan y sufren. Estas permanentes recepción, apropiación y re-significación situadas del proyecto escolar hacen que las prácticas y las experiencias escolares estén cargadas de sentidos, y de sentidos muy diversos, para quiénes las producen y las viven todos los días. (SUÁREZ, 2007).

Las escuelas están surcadas por discursos que actualizan y tratan de darle una dimensión y una temporalidad humanas, concretas, a ese sentido histórico socialmente disputado (DELORYMOMBERGUER, 2016). Algunos de esos discursos son oficiales: están dichos y escritos en el lenguaje técnico, pretendidamente objetivo, neutral, desafectado de subjetividad, que imponen las modalidades dominantes de gobierno educativo. Otras historias, en cambio, se cuentan, intercambian y comunican al ras de las experiencias que tienen lugar en las escuelas, y forman parte de su memoria pedagógica silenciada. Estas historias locales, mínimas, de maestros y alumnos de escuela, se narran con las mismas palabras, argumentos y estilos que usan los actores de las experiencias para nombrarlas, ordenarlas, otorgarles sentido y valor. Se dicen, escuchan y escriben en el juego de lenguaje de la práctica, y están situadas en el espacio y el tiempo de las escuelas y de las experiencias educativas a las que refieren (SUÁREZ, 2016).

El mundo de las escuelas puede ser imaginado, entonces, como un mundo de la vida (GADAMER, 2012). Esto es, como unos espacios, unos momentos y unos sucesos que dotan a ese territorio de coloraciones vívidas y particulares, y que son habitados por unos sujetos que heredan y configuran tramas de sentido para configurarlo y significarlo de manera peculiar. Más allá de su pertenencia a un sistema, su filiación a un currículum oficial y su adscripción a un formato relativamente homogéneo y persistente en el tiempo (la "forma escolar"), la escuela singular, la "escuelita" que se experimenta, se vive y se recrea en el mundo, para ser conocida requiere ser contada, descripta, narrada y documentada en su singularidad socio-histórica y en su particular transcurrir en el tiempo (ROCKWELL, 2009). Las escuelas están constituidas por acontecimientos de diversa índole, pero casi todas las cosas que suceden en ella se relacionan de una forma $u$ otra con la vida pasada, presente y futura de las personas que la habitan y la hacen: los docentes y los alumnos. Los sucesos del mundo escolar se entremezclan con sus historias, ilusiones, proyectos y circunstancias.

Por eso, la institución escolar puede ser estudiada tal como se estudian otras instituciones sociales caracterizadas por el trabajo con personas, o los dispositivos de poder y las tecnologías de socialización/individuación históricamente construidos, o los aparatos ideológicos del estado y la reproducción social de las desigualdades. Pero solo será conocida en profundidad en su dimensión humana, si es indagada e interpretada a través de las experiencias que viven y narran sus habitantes. 
En efecto, el mundo de la vida escolar está cargado, saturado, de historias, y los docentes son a un mismo tiempo los actores de sus intrigas, los protagonistas de la acción narrada y los autores de sus relatos. Y en ese narrar y ser narrados permanentes los maestros y profesores actualizan y recrean el sentido de la escolaridad, reconstruyen su identidad como colectivo profesional y transmiten el saber del oficio de enseñar (ALLIAUD, 2017). Al contar historias, los docentes hablan de sí mismos, de sus sueños, proyecciones y realizaciones, y narrándose cuentan sus saberes de experiencia y se desarrollan profesionalmente como docentes (SUÁREZ, 2006). Porque, tal como propone José Contreras “...nadie es docente, ni aprende a serlo en abstracto. Ser docente es siempre una historia personal" (CONTRERAS, 2016).

\section{CONVERSAR CON DOCENTES}

Conversar con un docente, o con un grupo de docentes, es una invitación a escuchar historias de escuela. Es un convite a detenerse y sumergirse en relatos en primera persona que narran experiencias escolares y que confiesan las sutiles percepciones de quienes las viven y cuentan (MC EWAN, 1998). Si esos relatos nos dicen acerca de sus primeras experiencias como docentes, o sobre los saberes pedagógicos que aprendieron trabajando, o sobre las dudas que provocó la enseñanza de un determinado contenido, posiblemente escucharemos la historia de alguna clase o acontecimiento escolar que recuerden especialmente, que les dejó marca, que los conmovió y que los movilizó a contar. Tal vez nos revelarán las reflexiones y las discusiones pedagógicas entre colegas que provocaron esas experiencias, o las dificultades que encontraron en su transcurso, o las estrategias didácticas que elaboraron o recrearon para lograr ciertos aprendizajes con un grupo de alumnos, o con aquél estudiante en particular.

Al narrar prácticas escolares que los tuvieron como uno de su protagonistas nos estarán contando parte de sus propias biografías profesionales y personales, y quizás también nos confíen sus perspectivas acerca de lo que consideran es el papel de la escuela, descripciones de las estrategias de trabajo más relevantes que vienen ensayando, la justificación pedagógica de los criterios de intervención curricular y docente que utilizan. Contándonos lo que les pasa con lo que acontece en el mundo escolar nos estarán mostrando, de primera mano, al ras de la historia, entramadas en la intriga del relato, las comprensiones pedagógicas que informan los modos en que emprenden cotidianamente su oficio, las maneras en que evalúan sus desempeños y afanes, las palabras y estilos que usan para nombrar los sujetos, objetos, prácticas y relaciones que tienen lugar en las escuelas (SUÁREZ, 2010). 
Con sus relatos e historias de la propia vida en las escuelas los docentes estarían tornando visible, documentable, disponible, parte del saber pedagógico práctico y muchas veces tácito que construyen en su carrera profesional. Por eso, si pudiéramos registrar, acopiar y analizar estos relatos podríamos conocer buena parte de las comprensiones pedagógicas de los docentes sobre la enseñanza y la escuela, sus recorridos profesionales y experiencias laborales, las palabras e historias que cuentan para darle sentido e interpretar sus mundos, sus inquietudes, sus deseos y sus logros. Podríamos documentar con cierta densidad una porción importante de aquellos aspectos de su biografía profesional que se entraman en el mundo de la vida de la escuela. Ampliando aún más la mirada y el horizonte, si pudiéramos organizar y compilar el conjunto de relatos de todos los docentes, si pudiéramos articularlos en una historia colectiva y disponerlos públicamente, seguramente obtendríamos una historia de la escuela y del currículum diferente a la que conocemos, a la que habitualmente se escribe y leemos. Sería una historia plural, alternativa y polifónica, en realidad sería una multiplicidad de historias sobre el hacer y pensar la escuela en términos pedagógicos y políticos (NÓVOA, 2003). En esta versión del currículum, más próxima a una memoria pedagógica del mundo escolar que a un recetario prescriptivo de la "buena enseñanza", conoceríamos la historia plural y heterogénea de las decisiones, discursos y prácticas que maestros y profesores protagonizan día a día, y que le imprimen un sentido situado, personal y biográfico a la experiencia de la escolaridad (SUÁREZ, 2003).

Sin embargo, a pesar del evidente interés que revisten para la reconstrucción de la memoria pedagógica de la escuela (SUÁREZ, 2005), la mayoría de estos relatos de experiencia se pierden, se olvidan o se desechan. En muchos casos porque no son siquiera escuchados, en otros porque son descalificados como parte de las anécdotas triviales que los docentes se cuentan en los bordes de la actividad escolar (en los recreos, en el colectivo, en las "horas libres", en las jornadas institucionales). Para la tradición de pensamiento pedagógico y escolar centrado en evaluar y acentuar "la calidad, la eficiencia y el control" del trabajo docente, hoy dominante, esos relatos e historias docentes forman parte de las dimensiones subjetivas que hay que controlar y ajustar para que la innovación y la mejora educativa sean posibles. Los objetivos de la reforma tecnocrática exigen eficiencia técnica, pericia operativa, respeto de los ritmos innovadores, y también disciplinamiento y silencio de sus ejecutores. De esta manera, la mayor parte del saber reflexivo, experiencial y potencialmente crítico, una porción importante de sus contenidos transferibles y quizás transformadores, se naturalizan en la cotidianeidad escolar o se degradan mediante anécdotas ingenuas y comentarios apresurados sin valor profesional y político. En los escenarios escolares que estas tradiciones político-pedagógicas tienden a configurar, las experiencias, los saberes de 
experiencia y las palabras e historias de los docentes tienen poco lugar y la memoria pedagógica narrada de la escuela poco valor (SUÁREZ, 2003).

Pero la memoria pedagógica de la escuela se dificulta también porque gran parte de los docentes que llevan adelante experiencias educativas valiosas, no las registran, no las escriben, no las documentan. O si lo hacen (¡después de todo la vida escolar está llena de formas de registro y documentación!), no lo hacen a través de las formas, los soportes y los géneros que permiten recuperar al menos parte de la textura densa de lo que sucedió, les sucedió e interpretaron que sucedió y les sucedió los protagonistas de la acción. Cuando los docentes escriben en la escuela lo hacen siguiendo pautas preestablecidas y guiones prefigurados, repitiendo o copiando planificaciones didácticas, llenando planillas administrativas, completando informes solicitados, inscribiendo su palabra en un entramado burocrático, jerárquico y de control. Estos datos, informes y documentos son eficientes, operativos y forman parte del dispositivo de seguimiento y control de gestión del sistema escolar, pero la mayoría de las veces no ofrecen materiales sensibles y adecuados para la reflexión y la deliberación pedagógica, o para la toma de decisiones situadas en los ambientes pedagógicos singulares y cambiantes de las escuelas y las aulas. Los textos escolares escritos por docentes están estructurados con arreglo a requerimientos administrativos y de gobierno centralizado de la actividad de las escuelas, o bien están prefigurados por la lógica normativa-prescriptiva de la anticipación. En ambos casos, las experiencias que viven los docentes y alumnos tienden a ser fragmentadas y categorizadas a través de patrones de ponderación ajenos a la lógica y la práctica pedagógica (BOLÍVAR, 2002) y las voces y las palabras de los docentes son negadas y capturadas por el lenguaje técnico y burocrático. En el mismo movimiento, las reflexiones e interpretaciones pedagógicas de los actores escolares son negadas, inhibidas o desechadas por superfluas o desvirtuadas.

En cambio, cuando los docentes escriben relatos de experiencias pedagógicas relevantes y las historias escolares que narran en primera persona están bien construidas, esos documentos constituyen materiales inigualables para conocer lo que hacen, piensan, saben y sienten los que habitan el mundo de la vida escolar. En tanto narraciones profesionales que problematizan el acontecer escolar y el trabajo pedagógico desde la perspectiva de sus actores, son escrituras densamente significativas que llaman e incitan a la lectura reflexiva, el comentario interesado, la conversación informada, la interpretación recíproca, el intercambio de saberes, la discusión horizontal entre docentes. $\mathrm{Y}$ en tanto materiales comunicables que pueden ser acopiados $\mathrm{y}$ difundidos, manifiestan potencialidades inéditas para la reconstrucción de la memoria pedagógica de la escuela, del currículum en acción y de las experiencias de formación. Sin embargo, como 
vengo afirmando, esos cuerpos de saberes, relatos y experiencias muy pocas veces encuentran habilitaciones, estrategias y vías adecuadas para ser rescatados, sistematizados, recreados y comunicados por sus protagonistas y autores, y por otros docentes y sujetos del campo pedagógico. De esta forma, las posibilidades de documentar aspectos "no documentados" del mundo de la vida escolar se diluyen y, con ello, se desaprovechan oportunidades importantes para desarrollar la profesionalidad de los docentes y fortalecer la identidad y quehacer pedagógico de las escuelas.

\section{LA DOCUMENTACIÓN NARRATIVA DEL MUNDO ESCOLAR}

La documentación narrativa de experiencias pedagógicas (SUÁREZ, 2007, 2010 y 2016) desarrollada en redes de colaboración entre docentes e investigadores se dirige a generar las condiciones políticas, institucionales y técnicas para que los maestros y profesores puedan interrumpir sus rutinas y prácticas habituales, muchas veces capturadas por las exigencias de la gestión y el control, y puedan detenerse a reconocer, narrar y tornar públicamente disponibles las comprensiones y saberes pedagógicos que construyeron a lo largo de sus recorridos profesionales. La relevancia que adquiere como estrategia emergente de investigación-formación-acción docente (SUÁREZ, 2015) radica en el enorme potencial que contienen los relatos pedagógicos para enseñarnos a interpretar el mundo escolar desde el punto de vista de sus protagonistas, y en la eficacia de sus recaudos metodológicos para promover procesos de auto y co-formación entre pares que signifiquen desarrollo profesional centrado en la investigación de la práctica.

En tanto dispositivo de trabajo pedagógico, la documentación narrativa de experiencias escolares ha venido desarrollándose en Argentina y otros países de América Latina desde el año 2000, a través de una serie de proyectos que armonizan de manera diferente y en distintos grados, según el caso, estrategias de desarrollo curricular centrado en la experiencia y el saber pedagógico de los docentes (SUAREZ, 2003); modelos de transferencia universitaria y de asesoramiento académico a proyectos pedagógicos de colectivos de educadores (SUÁREZ, 2013); modalidades de investigación educativa y pedagógica que combinan principios teóricos y metodológicos de la etnografía de la educación (BATALLÁN, 2007; ROCKWELL, 2009), la investigación y narrativa de las prácticas escolares (BOLÍVAR, 2002; CONNELLY y CLANDININ, 1995), la investigación acción docente y la investigación participante (ANDERSON y HERR, 2007); y estrategias de formación y capacitación horizontal entre docentes (SUÁREZ y otras, 2004 y 2005).

Consiste básicamente en una estrategia de producción individual y colectiva de textos orientados a reconstruir de forma narrativa, difundir y debatir experiencias y prácticas educativas llevadas a cabo por los mismos docentes autores de los relatos en diferentes situaciones sociales, 
culturales, geográficas, históricas e institucionales. En el proceso de escritura, los docentes que protagonizaron experiencias pedagógicas en las escuelas se convierten en narradores de relatos e historias escolares, al mismo tiempo que tornan públicamente disponibles los saberes profesionales y las comprensiones pedagógicas que ponen a jugar en sus prácticas y cuando las recrean narrativamente. Se transforman en indagadores narrativos y autobiográficos de sus propias experiencias y mundos pedagógicos; se posicionan en el campo educativo como sujetos de discurso y saber pedagógico, como sujetos del currículum y como sujetos de su propia formación. Al escribir relatos de experiencia pedagógica se convierten en intérpretes pedagógicos del mundo escolar que habitan. Como se sabe, toda narración o testimonio autobiográfico ya suponen en sí mismos interpretación, construcción y recreación de sentidos, lecturas del propio mundo y de la propia vida. Cuando los docentes narran y vuelven a narrar por escrito experiencias pedagógicas vividas, les están otorgando sentidos particulares a lo que hicieron como docentes en el mismo movimiento en que re-elaboran reflexivamente sus vidas y se re-posicionan respecto de ellas, ya más distanciados que cuando las vivieron. A través de esos relatos proyectan sus expectativas, preguntas y preocupaciones; las dicen, las escriben, las comparten y conversan con otros colegas en el lenguaje de la práctica, con sus propias palabras, para pensarlas de nuevo y renombrarlas en un nuevo relato. Se ven en ellas y a través de ellas; también ven a los otros, los nombran y caracterizan; revisan y discuten las certezas y las dudas que edificaron y desbarataron a lo largo de sus desempeños en las escuelas y las aulas.

Cuando escriben, dan a leer, conversan y re-escriben sus relatos de experiencia los docentes de la documentación narrativa descubren sentidos pedagógicos parcialmente ocultos o ignorados; atisban cuestiones pedagógicas todavía sin nombrar o nombradas de maneras poco adecuadas; reconocen prejuicios improductivos que hacer reiterar el error más allá de la voluntad; reconfiguran el mundo de la experiencia escolar y vuelven a nombrarla y a leerla, a re-interpretarla. En la medida en que consiguen distanciarse de su práctica para tornarla objeto de pensamiento y discurso, para hacerla material de escritura, lectura e interpretación pedagógica, en la medida en que pueden documentar algunos de sus aspectos "no documentados" o invisibilizados, los docentes narradores se dan cuenta de lo que saben, de lo que no conocen, de lo que no pueden nombrar y de lo que pueden hacer. Ponen en tensión su sabiduría práctica, la componen y recomponen, la objetivan, la fijan en escritura, la leen, la comunican, la critican (SUÁREZ, 2010). Por eso, en el movimiento de “dar a leer" sus relatos pedagógicos, los docentes narradores entregan sus propias lecturas acerca de lo que pasó en la escuela y lo que les pasó como docentes, educadores, pedagogos. Dan a conocer parte de sus vidas profesionales, de sus mundos escolares y pedagógicos, de su sabiduría 
profesional secreta. Al disponer públicamente sus relatos escritos de experiencias, los docentes narradores colaboran a reconstruir la memoria pedagógica de la escuela, a conocer cualitativamente el mundo de la vida escolar y a interpretar los discursos y prácticas que lo constituyen.

\section{MOMENTOS DE LA EXPERIENCIA DE DOCUMENTAR EL MUNDO ESCOLAR}

A diferencia de otros tipos de relatos pedagógicos, las narrativas de los docentes que viven la experiencia de documentar sus mundos escolares no se producen de forma espontánea, ni son concebidos mediante la redacción libre y desinteresada de los educadores. Por el contrario, aun cuando los participantes de la documentación narrativa muestran desde el inicio su disposición para la escritura, lectura y publicación de relatos autobiográficos, y se manejan con autonomía para elegir los temas, estilos y modulaciones de sus narraciones, indagan el mundo escolar y elaboran sus textos pedagógicos en condiciones bastante específicas. Un dispositivo de investigaciónformación-acción docente participativo, entre pares y en redes de colaboración, organiza y regula los tiempos, espacios y recursos teóricos y metodológicos para la producción, circulación y rcpeción de las historias. Este dispositivo y la coordinación y asesoramiento permanentes de un equipo de investigadores universitarios son los que garantizan la adecuación de los prácticas de escritura, lectura, comentario y conversación desplegadas a los principios y recaudos metodológicos de la indagación narrativa y la investigación interpretativa (SUÁREZ, 2007).

El itinerario de la documentación narrativa es complejo, trabajoso, y está permanentemente mediado por estrategias y técnicas de taller y de investigación acción y participante. Tal como lo hacen los "talleres de educadores que investigan las prácticas" (BATALLÁN, 2007) en los que se inspiran, los talleres y procesos de documentación narrativa trazan un recorrido que es guiado y acompañado por el equipo de coordinación. Ya sea a través de la producción de materiales gráficos y virtuales elaborados específicamente para orientar el proceso de documentación (SUÁREZ y OCHOA, 2004; SUÁREZ, OCHOA y DÁVILA, 2005), como mediante jornadas presenciales y virtuales con los docentes, la coordinación del proceso de formación e investigación acompaña y asesora a los docentes autores en muchos momentos decisivos. Asimismo, las instancias de trabajo colaborativo en red que promueve el dispositivo, en las que otros docentes narradores leen, comentan e interpretan los relatos pedagógicos elaborados por cada uno, funcionan como momentos reflexivos y mediaciones metodológicas colectivas de las decisiones de la escritura y la documentación desplegadas individualmente. No obstante esta persistente asistencia, diseñada a la manera de "trabajo de campo", los docentes involucrados en la documentación de sus prácticas 
cuentan a lo largo del trayecto con un amplio margen de posibilidades y oportunidades para autoorganizar institucional, grupal y privadamente sus respectivas producciones textuales.

Más allá de la forma particular que ese trayecto de investigación narrativa y formación entre pares tome en cada caso, es posible identificar y describir una serie de momentos o instancias de trabajo, no necesariamente sucesivos y la mayoría de las veces recursivos, que permitirán una comprensión más acabada de las complejas operaciones intelectuales en las que se comprometen los docentes narradores (SUÁREZ, 2007).

\section{GENERACIÓN DE CONDICIONES}

La generación y el sostenimiento de condiciones institucionales y habilitaciones en los sistemas escolares y las escuelas para que los docentes puedan involucrarse activamente en procesos de documentación narrativa con el apoyo de las administraciones educativas es un momento decisivo del dispositivo. Esta estrategia de trabajo pedagógico, indagación narrativa del mundo escolar y formación continua de docentes supone una ruptura con las modalidades convencionales de organización del trabajo docente y con el flujo rutinario de las actividades escolares. Implica inventar tiempos, recrear espacios y convenir arreglos normativos y micropolíticos que garanticen oportunidades de escritura, lectura, conversación y trabajo colaborativo entre docentes y entre éstos e investigadores universitarios que, la mayoría de las veces, no están dados de antemano.

Para lograrlo, el dispositivo de la documentación narrativa prevé desde el principio y a lo largo del proceso el trabajo conjunto de investigadores, docentes y referentes de administraciones educativas para lograr acuerdos y establecer reglas de juego que hagan posible la producción narrativa de los docentes. Este momento del dispositivo incluye la "invitación" de los docentes a integrarse al trabajo colaborativo que requiere una explicitación clara de los compromisos a asumir por ellos y de las garantías y certificaciones dispuestos por el gobierno escolar para que su participación resulte viable. Las gestiones políticas de la educación preocupadas por la democratización de la producción, distribución y acceso al conocimiento sobre la enseñanza tienen un papel fundamental para habilitar y crear condiciones para que otras formas de construcción y difusión del saber pedagógico sean posibles.

\section{Identificar y seleccionar}

Identificar y seleccionar las prácticas pedagógicas y las experiencias escolares a relatar y documentar es el momento del itinerario de investigación-formación-acción docente que comienza 
a desarrollarse mediante la escritura, la lectura, el comentario y la conversación entre pares. En un primer momento del proceso, esta instancia de trabajo es estratégica en la medida en que supone la negociación y la conciliación de los intereses de indagación, muchas veces divergentes, de las administraciones escolares, los investigadores académicos y los docentes narradores. Pero también es importante a lo largo de todo el trayecto de la documentación, por un lado, porque el mismo proceso individual y colectivo de reflexión e interpretación de los relatos puede redireccionar el interés del docente narrador hacia otras experiencias vividas, y por otro, ya que una vez seleccionada la experiencia a relatar resulta necesario un persistente y también reflexivo trabajo de identificación de los componentes a incorporar (personajes, escenarios, contextos, voces) en la configuración de la intriga narrativa del relato pedagógico en cuestión.

En ambos casos, el docente narrador debe hurgar en la memoria personal y en la de otros docentes e informantes clave de la experiencia a relatar, así como relevar y registrar huellas y rastros materiales de las prácticas pedagógicas desplegadas efectivamente durante las propias trayectorias profesionales. Es en esta instancia donde las "técnicas de recolección de datos" propios de la investigación narrativa y etnográfica (notas de campo, entrevistas en profundidad, conversaciones con informantes clave, diarios profesionales, fotografías, videos, audios) contribuyen a informar empíricamente los relatos y a tomar de decisiones de escritura y re-escritura que impactan sobre sus sentido y contenidos sustantivos.

\section{Escribir y re-escribir}

Otro momento identificable del dispositivo de la documentación narrativa tiene que ver con la escritura y re-escritura de los docentes participantes de distintos tipos de texto y versiones sucesivas de relatos de la experiencia pedagógica a documentar, hasta llegar a una versión "publicable". En este momento decisivo de la documentación narrativa, los docentes llevan adelante una serie sucesiva de producciones textuales que toman como insumo central o "datos" a los relatos orales producidos por los informantes clave, pero que también tienen en cuenta a los recuerdos que se disparan al escribir y re-escribir y a otros registros materiales y virtuales de la experiencia (“material empírico").

Es el momento en el que se "fija" textualmente a la experiencia, en el que ésta alcanza su mayor grado de objetividad, y al mismo tiempo, en el que los docentes, informados por las lecturas, los comentarios y las conversaciones con sus colegas y los coordinadores, componen, recomponen y dotan de densidad a la intriga narrativa que articula y da sentido de totalidad a los distintos sucesos de la experiencia. También es el momento más solitario y reflexivo, en el que por lo general 
los docentes trabajan individualmente y se posicionan como autores de relatos de experiencia. No obstante, es la instancia en la que los aportes de los otros momentos de la documentación, todos ellos comprometidos con formas de trabajo colectivo y colaborativo entre pares, contribuyen a profundizar la indagación narrativa y autobiográfica del docente participante y, consecuentemente, a la persistente y reflexiva reescritura del relato hasta el momento de su disposición pública a través de medios situacionales, gráficos y electrónicos.

\section{Editar: leer, comentar y conversar}

Otro momento es el que podemos llamar "edición pedagógica" de los relatos de experiencia o documentos narrativos. La edición pedagógica implica una compleja trama de operaciones muy específicas, orientadas a colaborar e incidir en las sucesivas y recursivas producciones textuales del relato pedagógico realizadas por cada docente autor, por lo que se encuentra totalmente relacionada con sus ritmos, dinámica y lógica. La edición pedagógica de relatos docentes supone entre otras cosas:

$\checkmark$ lecturas y relecturas propias y de otros docentes, individuales y colectivas, de las versiones parciales y final del relato;

$\checkmark$ la interpretación y la reflexión pedagógicas en torno a la experiencia pedagógica reconstruida y narrada;

$\checkmark$ la conversación y la deliberación pedagógica entre pares cercanos, en un ámbito grupal colaborativo y empático, en torno de las experiencias y comprensiones pedagógicas construidos en ellas y reconstruidos narrativamente en los relatos pedagógicos;

$\checkmark$ la elaboración y comunicación al docente autor de observaciones, preguntas, sugerencias y comentarios escritos y orales, individuales y colectivos, sobre el relato pedagógico en cuestión;

$\checkmark$ la toma de decisiones respecto de la comunicabilidad del relato pedagógico y acerca de la pertinencia y oportunidades de su publicación (gráfica y/o virtual) y de su difusión en circuitos especializados y docentes.

Como puede apreciarse, la edición pedagógica recoge muchas de las recomendaciones metodológicas de la investigación interpretativa, etnográfica y narrativa, y se diferencia de una tradicional "corrección de estilo". De esta manera, si bien son consideradas las reglas de estilo, ellas son aplicadas de modo complementario y en sintonía con la edición pedagógica de cada relato singular. Los partícipes centrales de la edición pedagógica son, una vez más, los docentes narradores y sus relatos pedagógicos y aquellos docentes editores que, de alguna forma u otra, ofrecen miradas específicas y generosas de la comunidad de prácticas y discursos en la que se inscribe, narra e interpreta la experiencia pedagógica en cuestión. 


\section{Publicar}

Otro momento decisivo de la documentación narrativa tiene que ver con la publicación del relato de la experiencia pedagógica. Es decir, con el acontecimiento político-pedagógico de tornarlo públicamente disponible y en el mismo movimiento transformarlo en "documento pedagógico público". La narración de experiencia construida por el docente autor en la intimidad de la comunidad de docentes escritores y editores de relatos pedagógicos, en circunstancias relativamente controladas, donde la cercanía y la comunicación directa lo contenían y protegían de lecturas "extranjeras", se constituye en un documento público y se inscribe en el debate político y especializado de la educación.

Paradójicamente, en el momento en que los docentes narradores se posicionan y afirman más que nunca como autores de experiencias, saberes y relatos pedagógicos, al mismo tiempo pierden el "control" sobre su texto ya que, al pertenecer ahora al ámbito de lo común, el relato ya se encuentra fuera de su dominio y alcance directos, ha trascendido la familiaridad del colectivo de pares y se ha tornado un objeto alienado de su autor. Ya no está al alcance de la mano, ni es posible reponer sentidos de manera oral y autorizada. Es por ello que las decisiones sobre la publicación del relato también requieren la mirada atenta del colectivo de docentes e investigadores, exigen procesos de deliberación y debate acerca de su comunicabilidad y suponen la previsión de los posibles públicos lectores del relato.

\section{Circular}

Otro momento fundamental tiene que ver con el hacer circular los documentos narrativos de experiencias pedagógicas en diferentes circuitos de difusión y recepción, y bajo distintos formatos (electrónicos, gráficos, fílmicos, interactivos), a fin de aprovechar las potencialidades pedagógicas e interpretativas de los relatos escritos por docentes y dar a conocer los saberes y comprensiones construidos durante las prácticas pedagógicas que en ellos se encuentran documentados. La circulación de las narraciones pedagógicas por diferentes circuitos del aparato escolar o del campo pedagógico, y su eventual utilización como materiales de la formación continua de docentes y del desarrollo curricular centrado en las experiencias y los saberes de los docentes, o como insumos críticos para la investigación narrativa e interpretativa del mundo escolar, son un momento decisivo del itinerario de la documentación que demanda, como en la fase de generación de condiciones políticas e institucionales, la activa participación de distintos actores de los sistemas escolares como gestores y facilitadores del proceso. 
Como se puede observar en esta descripción esquemática, el proceso metodológico de la documentación narrativa excede por mucho a la escritura individual y solitaria de los profesores, maestros y demás educadores. Documentar narrativamente experiencias pedagógicas no es solamente escribir, y mucho menos escribir solo y aisladamente. Siempre supone la constitución de un colectivo de docentes narradores y, fundamentalmente, el ejercicio reflexivo de la lectura, la conversación y la interpretación pedagógicas junto con otros colegas. Por eso, esta particular modalidad de trabajo pedagógico pretende combinar, por un lado, la generación de las condiciones político pedagógicas e institucionales para que la sistematización narrativa de la práctica pedagógica sea posible y, por otro, la disposición de las condiciones de tiempo, espacio y recursos para escribir, leer, escuchar, pensar y conversar entre docentes. Para hacerlo, se apoya en enfoques teóricos y estrategias metodológicas que se distancian de otros más convencionales y configura una propuesta de organización del trabajo docente que promueve otra política de conocimiento y de reconocimiento para la investigación, la formación y la práctica en el campo pedagógico (SUÁREZ, 2013).

\section{INVESTIGACIÓN PEDAGÓGICA, FORMACIÓN DOCENTE E INNOVACIÓN DESDE LA ESCUELA}

A diferencia de las formas más difundidas de relevamiento y sistematización de las prácticas educativas, que pretenden controlar las dimensiones "subjetivas" puestas en juego por los actores en su experiencia escolar por entender que su singularidad estaría minando la "objetividad" o la "neutralidad" de la información sistematizada, la documentación narrativa procura integrar esos aspectos en la producción de los relatos. Movida por intereses e interrogantes pedagógicos e interpretativos, más que administrativos o de control, intenta resaltar aquellos aspectos que justamente hacen únicas e irrepetibles a las experiencias vividas por los profesores y los maestros en las escuelas, y a las comprensiones e interpretaciones que éstos construyen acerca de ellas. De esta manera, además de presentarse como una estrategia de formación horizontal y de desarrollo profesional de docentes, lo hace como una particular modalidad de investigación-acción participante entre docentes. Y como estas tradiciones de investigación sugieren, pretende reconstruir y mostrar los sentidos pedagógicos y los entendimientos sociales y culturales que los docentes construyen y recrean cuando escriben, leen, reflexionan y conversan entre colegas acerca de sus propias prácticas y sus propios mundos.

Sólo en el sentido de que "algo diferente suceda" con las prácticas escolares y los docentes, el proyecto de documentar narrativamente las experiencias pedagógicas se presenta como 
innovador. Se propone, más bien, innovar en las formas de interpelar, convocar y organizar el trabajo de los docentes para la re-construcción de la memoria pedagógica de la escuela, así como en las modalidades de gestión de los sistemas escolares para objetivarla, legitimarla y difundirla. Propone otras formas de trabajo y gestión escolares que brinden no sólo la posibilidad de anticipar, prever y controlar, sino también de volver sobre lo hecho a través de la escritura como vía para la reformulación, la ampliación y la transformación de la propia práctica. Por eso, el registro, la sistematización escrita, el acopio y la difusión pública de experiencias, prácticas y saberes escolares, contadas a través de la voz y palabra de los docentes, constituyen al mismo tiempo una propuesta político pedagógica para la escuela y un programa para la formación docente continua y el desarrollo profesional entre docentes. En efecto, al estimular entre los docentes y garantizar procesos de escritura, lectura, conversación, reflexión e interpretación pedagógica de sus propias experiencias escolares, se espera no sólo acopiar y difundir un corpus de documentos y conocimientos distintos a los habituales, sino también hacer posibles experiencias de formación horizontal que signifiquen el desarrollo profesional de los involucrados y una contribución para la transformación democrática de la escuela.

La propuesta, entonces, consiste en habilitar otros espacios, tiempos y condiciones para pensar y actuar sobre la escuela, y hacer posible otras relaciones entre los actores de los sistemas escolares, que permitan comprender y problematizar algunos aspectos significativos de la vida escolar que las estrategias vigentes no tienen presentes. Esto significa, entre otras cosas, revalorizar el papel de los maestros y profesores en su propia formación, y dejar atrás las modalidades de capacitación ideadas desde el supuesto del déficit. Además, a través de las redes de docentes y escuelas trazadas por la circulación pública y recepción de estos documentos pedagógicos, la propuesta se orienta a constituir una comunidad de docentes escritores, lectores e intérpretes de experiencias pedagógicas. Una comunidad de pedagogos que habilite otras formas de “alfabetización docente", para que los docentes escriban y lean relatos pedagógicos en sus propias palabras, en su mismo lenguaje, entre ellos, para comprender mejor y transformar el mundo escolar que habitan.

Documentar experiencias pedagógicas habilita la comunicación y circulación de ideas, conocimientos y proyectos que interpelan a los docentes en su profesionalidad y en su protagonismo como actores centrales de las prácticas pedagógicas de las escuelas. Supone, al mismo tiempo, reconocer el carácter cambiante y particular que adopta como investigaciónformación-acción docente participativa de acuerdo a los contextos en los que se desarrolla, así como atender las potencialidades de transferencia y adecuación de esas experiencias a otros contextos y 
situaciones escolares, con el propósito de que sea posible la construcción de una memoria pedagógica de la escuela, de las prácticas escolares y docentes, pero de otro modo y desde otra perspectiva. 


\section{BIBLIOGRAFÍA}

ALLIAUD, Andrea. (2017). Los artesanos de la enseñanza. Acerca de la formación de maestros de oficio. PAIDOS: Buenos Aires.

ANDERSON, Gary; HERR, Kathryn. (2007). "El docente-investigador: la investigación-acción como una forma válida de generación de conocimientos”. En: SVERDLICK, Ingrid. (Comp.). La investigación educativa. Buenos Aires: Noveduc.

BATAllÁN, Graciela. (2007). Docentes de infancia. Antropología del trabajo en escuelas primarias. Buenos Aires: Paidós.

BOLÍVAR, Antonio. (2002). De nobis ipsis silemus?: Epistemología de la investigación biográfico-narrativa en educación”. En: Revista Electrónica de Investigación Educativa, vol. 4, n. 1.

CONNELLY, F. Michael; CLANDININ, D. Jean. (1995). Relatos de experiencia e investigación narrativa. En: LARROSA, Jorge. Déjame que te cuente. Ensayos sobre narrativa y educación. Barcelona: Laertes.

CONTRERAS, José. (2016): Profundizar narrativamente la enseñanza. En: BRAGANCA, I.; BARRETO ABRAHAO, M.H.; SANTOS FERREIRA, M. (Orgs.). Perpectivas epistémico-metodológicas da pesquisa (auto)biográfica. São Paulo: Editora CRV.

DELORY-MOMBERGUER, Christine. (2016). La condición biográfica. Ensayos sobre el relato de sí en la modernidad avanzada. Medellín Editorial: Universidad de Antioquia.

GADAMER, Hans-Georg. (2012). Verdad y método. Salamanca: Sígueme.

McEWAN, Hunter. (1998). Las narrativas en el estudio de la docencia. En: MCEWAN, H.; EGAN, K. (Comps.). La narrativa en la enseñanza, el aprendizaje y la investigación. Buenos Aires: Amorrortu.

NÓVOA, Antonio. (2003). Textos, imágenes y recuerdos. Escritura de 'nuevas' historias de la educación. En: POPKEWITZ, T.; FRANKLIN, B.; PEREYRA, M. (Comps.). Historia cultural y educación. Ensayos críticos sobre conocimiento y escolarización. Barcelona: Pomares Corredor.

ROCKWELL, Elsie. (2009). La experiencia etnográfica: historia y cultura en los procesos educativos. Buenos Aires: Paidós.

SUÁREZ, Daniel H. (2016). La documentación narrativa de experiencias pedagógicas y la democratización del campo educativo en Argentina. En: BRAGANCA, I.; BARRETO ABRAHAO, M.H.; SANTOS FERREIRA, M. (Orgs.). Perpectivas epistémico-metodológicas da pesquisa (auto)biográfica. São Paulo: Editora CRV.

(2015). Relatos de experiencia, redes pedagógicas y prácticas docentes: documentación narrativa de experiencias escolares en el nivel inicial. En: MURILLO ARANGO, G.J. (Comp.). Narrativas de experiencia en educación y pedagogía de la memoria. Buemos Aires: Editorial FFyL-/UBA-Editorial Universidad de AntioquiaCLACSO.

(2010). La documentación narrativa de experiencias pedagógicas como estrategia de indagación-acciónformación de docentes. En: PASSEGGI, M.C.; DE SOUZA, E.C. (Orgs.). Memoria docente, investigación y formación. Buenos Aires: Editorial FFyL-UBA/Clacso.

(2007). Docentes, narrativa e investigación educativa. La documentación narrativa de las prácticas docentes y la indagación pedagógica del mundo y las experiencias escolares. En: SVERDLICK, Ingrid. (Comp.). La investigación educativa. Buenos Aires: Noveduc.

(2006). Documentación narrativa de experiencias pedagógicas. Una manera de indagar el mundo y la experiencia escolares. En: Entre Maestros, La UPN de México, vol. 5, n. 16.

(2003). Gestión del currículum, documentación de experiencias pedagógicas y narrativa docente. Rio de Janeiro: OLPEd del LPP-UERJ. Disp.: <www.lpp-uerj.net/olped>.

; OCHOA, Liliana. (2005). La documentación narrativa de experiencias pedagógicas. Una estrategia para la formación de docentes. Buenos Aires: MECyT/OEA.

; OCHOA, Liliana; DAVILA, Paula. (2004). Manual de capacitación sobre registro y sistematización de experiencias pedagógicas. Buenos Aires: MECyT/OEA. 


\section{RESUMEN}

El artículo presenta a la documentación narrativa de experiencias pedagógicas como una modalidad de investigación-formación-acción docente participativa y en redes de colaboración, que podría estar colaborando en la reconstrucción de la memoria pedagógica de la escuela y a una comprensión más sutil de su acontecer. Para ello, caracteriza a las experiencias que tienen lugar en las escuelas como cargadas de significado y valor para los que las viven, y como un mundo de la vida singular atravesado e interpelado por discursos de distinto tipo y en disputa. También explora las potencialidades interpretativas, formativas e investigativas de los relatos de experiencia y anticipa una serie de cuestiones metodológicas vinculadas con el dispositivo de la documentación narrativa, así como delimita los alcances de las modalidades convencionales de documentación escolar. Finalmente, describe los momentos del trayecto delimitado por los procesos de documentación narrativa y perfila algunas de sus contribuciones al campo de la investigación educativa, el currículum y la formación de docentes.

Palabras claves: DOCUMENTACIÓN NARRATIVA - RELATOS DE EXPERIENCIA - MEMORIA PEDAGÓGICA MUNDO ESCOLAR.

Submetido em Jul/2017

Aceito em Set/ 2017 